DOI: 10.12731/2227-930X-2021-11-2-100-114 УДК 338:004

\title{
ВНЕДРЕНИЕ ЦИФРОВЫХ ТЕХНОЛОГИЙ КАК ФАКТОР ПОВЫШЕНИЯ ЭФФЕКТИВНОСТИ РАБОТЫ ТРАНСПОРТНО-ЛОГИСТИЧЕСКИХ СИСТЕМ
}

\author{
Зарипова P.C., Рочева O.A., \\ Хамидуллина Ф.Р., Арбузова М.В.
}

В условиях развития циифровой экономики логистика является неотьемлемой и важной частью, поэтому инновации в данной сфрере помогут увеличить доход предпринимателей и облегчить хранение и транспортировку товаров. Вопросы внедрения и финансирования логистических инноваций являются достаточно актуальныли и обширными. Развитие цифровой экономики вынуждает транспортно-логистические предприятия производить оцифровку многих своих процессов деятельности. Все современные тенденции развития логистики связаны с внедрением и интенсивным развитием ичифровых технологий, которые способствуют удовлетворению быстрорастущих потребностей потребителей. Современные цифровые технологии приводят к трансформации иеепей поставок, и компании с традиционными подходами и технологиями в управлении логистикой уже не могут оставаться конкурентоспособными.

Цель - изучить и провести анализ прочесса внедрения инновационных технологий в сфере логистики и управлении цепями поставок.

Методология проведения работы. В статье использовались экономико-математические методы, системный подход и обобщение; аналитические и статистические методы анализа.

Результаты. В статье проведен анализ применения инновационных технологий в сфере логистики и управлении цепяли поставок; рассмотрены примеры использования инновачий и информаџионно-коммуникационных технологий транспортно-логистическими 
предприятиями в своей деятельности; доказано, что внедрение инновачий и информаџионно-коммуникационных технологий в сфере логистики и грузоперевозок выгодно для повышения эффективности рабочего прочесса, хранения данных, сокращения длительности логистического цикла, управления поставками товаров, снижения ошибок в документообороте и его длительности.

Область применения результатов: полученные результаты целесообразно применять экономическими субъектами, осуществляющими деятельность в сфере логистики и управлении цепями поставок.

Ключевые слова: логистика; поставка товара; грузоперевозки; ичепи поставок; инновации; цุифровизащия; логистические системь

\title{
DIGITALISATION AS A FACTOR TO IMPROVE THE EFFICIENCY OF TRANSPORT AND LOGISTICS SYSTEMS
}

\author{
Zaripova R.S., Rocheva O.A., \\ Khamidullina F.R., Arbuzova M.V.
}

With the development of a digital economy, logistics is an integral and important part, so innovations in this area will help to increase entrepreneurial income and facilitate the storage and transportation of goods. The issues of implementing and financing logistics innovation are quite relevant and extensive. The development of the digital economy is forcing transport and logistics companies to digitise many of their business processes. All current logistics trends are related to the introduction and intensive development of digital technologies, which contribute to meeting the fast-growing needs of consumers. Today's digitalisation is transforming the supply chain and companies with traditional logistics management approaches and technologies can no longer remain competitive.

Purpose: examine and analyse the process of introducing innovative technologies in logistics and supply chain management. 
Methodology. The paper used economic-mathematical methods, system approach and generalization; analytical and statistical methods of analysis.

Results. The article analyzes the application of innovative technologies in logistics and supply chain management; examines examples of the use of innovation and information and communication technologies by transport and logistics enterprises in their activities; proves that the introduction of innovation and information and communication technologies in logistics and freight transport is beneficial for improving workflow efficiency, data storage, reducing the duration of the logistics cycle, goods delivery management, reducing errors

Practical implications: the obtained results are appropriate to be applied by economic entities involved in logistics and supply chain management activities.

Keywords: logistics; commodity supply; freight; supply chain; innovation; digitalization; logistics systems

Сегодня мир стоит на пороге «Четвертого этапа цифровой революции» - «Индустрия 4.0». Неотъемлемой частью цифровой экономики, обеспечивающей товародвижение, является цифровая логистика и управление цепями поставок. Для реализация данной модели требуется проведение научных исследований, а также подготовка кадров, обладающих необходимыми интегральными компетенциями в данной области знаний и информационных технологий [2]. В странах - лидерах по внедрению цифровой экономики (США, Китае, Южной Корее, Великобритании, Японии, Франции) ведутся интенсивные научные исследования в области цифровой логистики и управления цепями поставок. Во многих вузах открыты новые образовательные программы для бакалавриата и магистратуры с названиями «цифровая логистика», «цифровое управление цепями поставок». Поскольку логистика входит в хозяйственную систему страны в качестве внутренней подсистемы, то, следовательно, при переходе России к цифровой экономике необходима адекватная трансформация логистических систем. 
Современная логистика меняется под влиянием множества факторов. Повышаются требования потребителей в скорости, качества и прозрачности процессов. В новых условиях экономическая конкурентоспособность страны и предприятий будет определяться наличием интеллектуальных транспортных и логистических систем, так как по оценкам экспертов логистическая составляющая в каждом конечном продукте занимает от $20 \%$ до $60 \%$.

Как и любая другая наука, логистика стремительно развивается под действием новых, инновационных тенденций. Изменениям подвергаются не только логистические модели, но и непрерывно появляются революционные технические инновации. Предметом инноваций в логистике является оптимизация траектории экономических потоков, циркулирующих в цепи, в целях сокращения времени логистического цикла, рационализации общих издержек товародвижения, повышения эффективности логистической цепи [7].

Будущее логистики не представляется без внедрения инновационных технологий в процесс управления потоками. Инновация рассматривается как какое-либо новшество, которое обеспечивает качественный рост эффективности работы процессов [1]. Исходя из этого определения, можно сделать вывод, что инновационную логистику следует рассматривать как деятельность, направленную на оптимизацию и повышение эффективности в области управления. Это самостоятельное направление, которое в первую очередь направлено на улучшение работы всей логистической системы. Кроме того, внедрение инноваций в логистические системы приводит к увеличению уровня конкурентоспособности фирмы, повышению лояльности среди покупателей, развитие экономики в рамках не только отдельного предприятия, но и страны в целом [4]. К таким новшествам можно отнести порядок хранения продукции на складе. Можно выстроить работу склада таким образом, чтобы на поиск определенного вида товара уходило меньшее количество времени. Такое направление называется матричная логистика, где основной акцент делается на матрицы, упорядоченные в определенном порядке и определенной логике. Складские матрицы полюбились не только иностранным менеджерам, но и 
российским за легкую адаптацию под потребности предприятия и возможность внесения постоянных корректировок [18].

Инновации в логистике подразумевают под собой также и технические разработки, которые помогают облегчить работу склада и транспортного отдела, увеличить прибыль организации. Примером такого нововведения является разработка французской компании «Savoye», которая занимается разработками новшеств в области логистических решений. Она представила новую упаковочную машину. Разработка называется «E-Jivaro». К её основным особенностям можно отнести то, что она сама производит расчеты для нужной высоты коробок, после чего сама их запечатывает.

Профессионалы разных стран сходятся во мнении, что логистические новшества стоит рассматривать не только с точки зрения революционных изменений во всей структуре логистической системы. Также не стоит забывать о локальных внедрениях в различных областях функционирования предприятия.

Инновационный подход в организации логистики направлен на использование современных информационно-коммуникационных технологий. Примером инноваций в сфере логистики является применение информационных технологий, которые успешно внедряются в транспортно-логистических предприятиях [17]. Информационные технологии позволяют автоматизировать весь жизненный цикл производства, анализировать грузопотоки, контролировать и вести учет. Стремительно растут масштабы логистики электронной коммерции, что способствует инновациям в применении информационных технологий в логистике на основе Интернета. Логистические инновации применяются в складском и транспортном хозяйстве, при распределении ресурсов в производстве, в производственном процессе, в управлении запасами, сбытовой деятельности, т.е. во всех функциональных областях логистики [3]. Соответственно можно сделать вывод, что область применения инноваций в логистике и управлении цепями поставок безгранична.

Цифровые логистические системы становятся частью виртуального рынка. Виртуальная и дополненная реальность, в которую вовле- 
чены различные инфраструктурные и поддерживающие организации, сервисные службы, поставщики и другие посредники, трансформирует способы взаимодействия друг с другом и с программными системами [16]. Цифровая трансформация логистических систем предопределяет необходимость решения задачи внедрения сквозных информационных технологий, построенных на единой транспортно-логистической, производственной и торговой инфраструктуре.

Примером инноваций, которые сейчас активно внедряются, являются беспилотные автомобили от «Google». Эта разработка поможет ускорить скорость транспортировки груза, так как автомобиль способен преодолевать расстояние более 4000 километров за 60 часов. К преимуществам беспилотных автомобилей относятся сокращение затрат на заработную плату и снижение уровня ДТП [4].

Умные очки «Google Glass» позволяют найти оптимальный маршрут для транспортировок и способны оперативно считывать штрих-коды. В очки вставлены специальные стекла с программным обеспечением для управления складом. Результаты работы в очках показали, что использование этой технологии способно сократить количество допущенных ошибок и одновременно увеличить скорость отбора продукции. К недостаткам очков относится хрупкость и дороговизна. К преимуществам относятся автономность, легкость в использовании, все функции доступны по голосовым командам.

В последние годы ускоряется формирование международной инфраструктуры: появляется спутниковая связь, новые навигационные системы, новые виды транспортных средств (мощные океанские лайнеры, высокоскоростные аэробусы и т.д.), расширяются ее масштабы и изменяется сама ее структура. На базе электроники, системы Интернет, космических спутников связи постепенно формируется глобальное киберпространство, глобальная система телекоммуникаций, планетарная информационная сеть.

Рассмотрим применение ещё одной новой технологии в логистике - технологии блокчейн. Технология блокчейн, идея о которой появилась в далеком 1991 году, на данный момент имеет много сфер применения [4]. И уже после популяризации биткоина на эту тех- 
нологию обратили внимание почти все. Началось бурное развитие, в котором многие пытались применить это у себя, вследствие этого в стартапы было инвестировано более 3 миллиардов долларов. Никто не сомневался, что за этим будущее. Но вскоре оказалось, что не везде и не всегда стоит применять эту технологию. В большинстве случаев это было не обосновано [5]. И по итогу, большинство стартапов так и закрылось, не начав внедрять свои продукты. Стало понятно, что блокчейн надо применять точечно и только после того, как обоснуют ее выгоду, можно уже внедрять в рабочие процессы.

Блокчейн представляет собой надёжный и эффективный способ обмена информацией контрагентов цепи поставок. Он создаёт неизменяемый цифровой реестр транзакций, который поддерживается распределённой сетью компьютеров. Платформы, работающие с использованием блокчейна, позволяют устранить посредников, управлять процессом взаимных платежей онлайн, отслеживать местонахождение грузов в режиме 24/7, быстро находить подходящий транспорт для доставки, находить груз для перевозчика и т. д.

На данный момент есть несколько перспективных сфер, чтобы начать тестировать продукты на основе блокчейна: логистика, ретейл, финансовые транзакции, оптимизация бизнес-процессов. Еще можно выделить сферу электронного документооборота [8].

Огромный интерес вызывает сфера логистики и ретейла, так как они взаимосвязаны друг с другом. Применение технологии блокчейн в этих сферах может оптимизировать все процессы, убрать лишних посредников, удешевить тем самым стоимость товара и увеличить лояльность покупателей. И если учесть, что можно будет сократить издержки и бракованные товары, то внедрение технологии блокчейн выглядит не просто прихотью, а необходимостью [6].

Логистика представляет собой сложный процесс, который является неотъемлемой частью торгово-рыночных отношений. Следовательно, логистика нуждается в постоянном усовершенствовании для обеспечения эффективности экономических процессов, в которые она вовлечена. Информационные технологии и интернет могут стать одним из источников таких необходимых преоб- 
разований. Применение технологии блокчейн в логистике может являться хорошим толчком для реализации задач цифровой экономики [9]. Например, в результате применения технологии блокчейн каждый товар получает «цифровой паспорт», что позволяет сократить риски и документооборот, вся информация для полного отслеживания продукции становится доступна на мобильных устройствах, повышается доверие покупателей и эффективность бизнеса. Блокчейн-платформа позволяет грузоперевозчикам отслеживать состояние заказов в режиме реального времени, помогает формировать счета, а искусственный интеллект полностью заменяет диспетчера и автоматически распределяет заказы между водителями. Благодаря такой платформе срок выполнения заказа уменьшается от 2-3 дней до 1 дня.

В мире ежегодно перевозятся миллиарды тонн товаров, но около 1,6 миллиардов тонн продуктов ежегодно считаются потерянными по разным причинам: просрочились, испортились, пропали или стали бракованными [4]. И очень часто эта проблема связана не столько со спецификой товара, а сколько с контролем его перевозки. Существующий рынок в основном работает по той же системе, что и в прошлом веке. Попытки оцифровать все данные и контроль приводят только к увеличению бюрократии и понижению эффективности сотрудников. Внедрение блокчейна должно снять часть проблем [5]. Из-за того, что блокчейну свойственны децентрализация и высокий уровень доверия за счет криптографических алгоритмов, он идеально вписывается в систему контроля за доставкой грузов [6]. Для того, чтобы контролировать местоположение груза, используются RFID-метки. Благодаря им всегда можно узнать местоположение товара, и при надобности дополнительные характеристики. К дополнению к RFID-меткам используются QR-коды, которые считываются телефоном и отправляться в систему для заполнения отчетности. В конце все процедуры получается товар с QR-кодом, который любой покупатель сможет отсканировать. И у него на устройстве появится подробная информация о данном товаре, вся история перевозок, весь список пунктов передачи. 
На данный момент уже есть разработки крупных компаний Walmart, IBM, Wave и др. Но массового распространения это пока не получило, так как разработка и найм квалифицированных кадров обходится очень дорого. На российском рынке пока не наблюдается больших проектов, связанных с технологией блокчейн, так как это новая область, и требуется время пока проекты выйдут на общественное обсуждение.

Таким образом, на сегодняшний день инновации играют важную роль в развитии предприятия [10]. Инновационная стратегическая логистика не менее актуальна и в России, однако она находится только в начале своего развития. Преимущества внедрения инноваций в сферу логистики прежде всего заметны благодаря повышению качества обслуживания, сжатию сроков в обработке и отгрузке заказов, а также сокращению сроков доставки до потребителя. За счет экономии времени можно отгрузить больше заказов, что приведет к увеличению прибыли для компании [11]. Назовём преимущества, которые появляются у компании при внедрении и функционировании информационной логистики: контроль за уровнем обслуживания покупателей; оценка эффективной работы персонала; повышение качественного уровня при транспортировке; сбор и анализ статистических данных; углубленное исследование рынка; снижение затрат; обеспечение гибкости и масштабируемости; видимость цепи поставок в реальном времени; более динамичная, безопасная и интерактивная цепь поставок; снижение затрат на цепочки поставок; сокращение административной рабочей силы.

Складская, транспортная, закупочная и сбытовая логистика уже не представляются без непрерывного использования информационных технологий [15]. Менеджерам сложно представить формирование и организацию работы цепей доставки информации между участниками транспортного процесса без возможностей быстрого реагирования на потребности рынка транспортных услуг.

Определяющим фактором в управлении становится скорость обработки данных и получение нужных сведений [12]. Оборот информации влияет на эффективность управления предприятием, его финансовые успехи. Практическая реализация инноваций 
в логистике становится мощным инструментом повышения конкурентоспособности предприятий и организаций, а также повышения конкурентоспособности, выпускаемой ими продукции и оказываемых услуг.

Несмотря на определенные попытки использования инновационных технологий на отечественных предприятиях, существует несколько препятствий для их развития в России:

- низкое качество базовой услуги транспортировки;

- недоинвестирование в развитие логистической инфраструктуры;

- пассивная инновационная политика;

- неповоротливый бюрократический аппарат;

- отсутствие интереса со стороны государства в поддержке инновационных проектов;

- низкая инновационная активность частного бизнеса;

- таможенные, тарифные и нормативно-правовые барьеры;

- недостаточный масштаб бизнеса логистических компаний.

Для решения названных выше проблем в развитии инновационной активности в сфере логистики в России необходимо стимулировать развитие логистической инфраструктуры за счет привлечения финансирования со стороны частных инвесторов, к числу которых можно отнести коммерческие банки, негосударственные пенсионные фонды и др [13].

Внедрение инноваций - это сложный, комплексный и длительный процесс. Компании нацелены на краткосрочную перспективу и не всегда готовы ждать результатов длительное время. Исследование оценки состояния логистических инноваций в отечественной экономике свидетельствует о том, что 51\% опрошенных компаний признают важность инноваций и технологий в логистике, но планируют заняться этой работой в среднесрочной перспективе, 38\% уже применяют инновационные решения в своей практике, 11\% занимают нейтральную позицию.

Подводя итог вышесказанному, подчеркнем, что современные вызовы ведения бизнеса диктуют необходимость использования 
инновационных решений при управлении цепями поставок, которые позволяют значительно увеличить производительность труда и сократить издержки [14]. Компания, отказывающаяся от внедрения инноваций, обречена на отставание и неконкурентоспособность. Можно сделать вывод, что в мире инновационные технологии в логистике и управлении цепями поставок являются очень важными для успешного и эффективного функционирования компаний и развития мировой экономики. Следует ожидать, что инвестиции в эту область продолжат расти в связи с необходимостью повышать конкурентоспособность компаний. Таким образом, применение новейших цифровых решений задает вектор для инновационного развития транспортных систем и комплексов с целью развития цифровой экономики в целом.

\section{Список литературы}

1. Алемасов Е.П., Зарипова Р.С. Влияние цифровизации на экономику предприятия // Наука Красноярья. 2020. Т. 9, № 2-4. С. 12-16.

2. Алемасов Е.П., Зарипова Р.С. Цифровизация промышленности как инструмент повышения производства // Информационные технологии в строительных, социальных и экономических системах. 2020. №2(20). C.107-109.

3. Зарипова Р.С., Пырнова О.А. Управление деятельностью организаций в условиях цифровой экономики // Ученые записки ИСГЗ. 2018. T.16, №2. С.70-75.

4. Набиуллин А.С., Зарипова Р.С. Применение технологии блокчейн для управления грузоперевозками // Наука Красноярья. 2020. Т. 9, №4-2. С. 106-110.

5. Набиуллин А.С., Зарипова Р.С. Цифровизация логистики с применением блокчейн // Информационные технологии в строительных, социальных и экономических системах. 2020. № 2 (20). С. 86-87.

6. Никитина У.О., Зарипова Р.С. Блокчейн как инструмент устранения посредников в торговых сделках // Наука Красноярья. 2019. Т.8, №5-3.С.107-110.

7. Шакиров А.А., Зарипова Р.С. Синергия логистической информационной системы и облачных вычислений // Информационные 
технологии в строительных, социальных и экономических системах. 2020. № 4(22). С. 60-62.

8. Шакиров А.А. Зарипова Р.С. Роль новых технологий в экономике XXI века: угрозы и вызовы цифровой экономики // «Экономика сегодня: современное состояние и перспективы развития (Вектор-2018)»: Сборник материалов Всероссийской научной конференции молодых исследователей. 2018. С. 331-334.

9. Шакиров А.А., Зарипова Р.С. Трансформация систем учета и контроля в условиях цифровой экономики // Наука Красноярья. 2019. T.8, №3-2. С.112-115.

10. Шакиров А.А., Зарипова Р.С. Особенности моделирования логистических систем // International Journal of Advanced Studies. 2019. T. 9, №4. С. 27-31.

11. Шакиров А.А., Зарипова Р.С. Актуальные проблемы автоматизации бизнес-процессов на предприятии // Наука Красноярья. 2020. T.9, №4-4. С.258-262.

12. Яппаров Р.Р., Зарипова Р.С. Внедрение информационных систем управления как инструмента организационной эффективности предприятий // Информационные технологии в строительных, социальных и экономических системах. 2020. № 4 (22). С. 27-29.

13. Cascetta E. Transportation Systems Engineering: Theory and Methods. Kluwer Academic Publishers, 2011. 742 p.

14.Zaripova R., Porunov A., Zinurova R., Galyamov R., Stepanova G. The Role of Practice-Oriented Education in the Development of the Country's Economy // New Silk Road: Business Cooperation and Prospective of Economic Development (NSRBCPED 2019), Advances in Economics, Business and Management Research. 2019. Vol. 131. P. 663.

15. The Demand for Public Transit: A Practical Guide, Transportation Research Laboratory, Report TRL 593, 2004. 246 p.

16. Goodwin P., Dargay J., Hanly M. Elasticities of Road Traffic and Fuel Consumption with Respect to Price and Income: A Review // Transport Reviews. 2004. Vol. 24, No. 3, P. 275-292.

17. Ortúzar J. de L., Willumsen L.G. Modelling Transport. John Wiley \& Sons Ltd., 2011. 586 p. 
18. Paulley N., Balcombe R., Mackett R. et al. The demand for public transport: The effects of fares, quality of service, income and car ownership // Transport Policy. 2006. Vol.13, No. 4. P. 295-306.

\section{References}

1. Alemasov E.P., Zaripova R.S. Nauka Krasnoyar'ya, 2020, vol. 9, no. 2-4, pp. 12-16.

2. Alemasov E.P., Zaripova R.S. Informatsionnye tekhnologii v stroitel'nykh, sotsial'nykh i ekonomicheskikh sistemakh, 2020, no. 2(20), pp. 107-109.

3. Zaripova R.S., Pyrnova O.A. Uchenye zapiski ISGZ, 2018, vol. 16, no. 2, pp.70-75.

4. Nabiullin A.S., Zaripova R.S. Nauka Krasnoyar'ya, 2020, vol. 9, no. 4-2, pp. 106-110.

5. Nabiullin A.S., Zaripova R.S. Informatsionnye tekhnologii v stroitel'nykh, sotsial'nykh i ekonomicheskikh sistemakh, 2020, no. 2 (20), pp. 86-87.

6. Nikitina U.O., Zaripova R.S. Nauka Krasnoyar'ya, 2019, vol. 8, no. 5-3, pp. 107-110.

7. Shakirov A.A., Zaripova R.S. Informatsionnye tekhnologii v stroitel'nykh, sotsial'nykh i ekonomicheskikh sistemakh, 2020, no. 4(22), pp. 60-62.

8. Shakirov A.A. Zaripova R.S. «Ekonomika segodnya: sovremennoe sostoyanie i perspektivy razvitiya (Vektor-2018)»: Sbornik materialov Vserossiyskoy nauchnoy konferentsii molodykh issledovateley ["Economy today: current state and development prospects (Vector-2018)": Collection of materials of the All-Russian scientific conference of young researchers]. 2018, pp. 331-334.

9. Shakirov A.A., Zaripova R.S. Nauka Krasnoyar 'ya, 2019, vol. 8, no. 3-2, pp. 112-115.

10. Shakirov A.A., Zaripova R.S. International Journal of Advanced Studies, 2019, vol. 9, no. 4, pp. 27-31.

11. Shakirov A.A., Zaripova R.S. Nauka Krasnoyar'ya, 2020, vol. 9, no. 4-4, pp. 258-262. 
12. Yapparov R.R., Zaripova R.S. Informatsionnye tekhnologii v stroitel'nykh, sotsial'nykh i ekonomicheskikh sistemakh, 2020, no. 4 (22), pp. 27-29.

13. Cascetta E. Transportation Systems Engineering: Theory and Methods. Kluwer Academic Publishers, 2011. 742 p.

14.Zaripova R., Porunov A., Zinurova R., Galyamov R., Stepanova G. The Role of Practice-Oriented Education in the Development of the Country's Economy. New Silk Road: Business Cooperation and Prospective of Economic Development (NSRBCPED 2019), Advances in Economics, Business and Management Research, 2019, vol. 131, pp. 663.

15. The Demand for Public Transit: A Practical Guide, Transportation Research Laboratory, Report TRL 593, 2004, 246 p.

16. Goodwin P., Dargay J., Hanly M. Elasticities of Road Traffic and Fuel Consumption with Respect to Price and Income: A Review. Transport Reviews, 2004, vol. 24, no. 3, P. 275-292.

17. Ortúzar J. de L., Willumsen L.G. Modelling Transport. John Wiley \& Sons Ltd., 2011, 586 p.

18. Paulley N., Balcombe R., Mackett R. et al. The demand for public transport: The effects of fares, quality of service, income and car ownership. Transport Policy, 2006, vol. 13, no. 4, pp. 295-306.

\section{ДАННЫЕ ОБ АВТОРАХ}

Зарипова Римма Солтановна, доцент, кандидат технических наук

Казанский государственный энергетический университет ул. Красносельская, 51, г. Казань, Татарстан, 420066, Российская Федерация

zarim@rambler.ru

Рочева Ольга Александровна, ст. преподаватель кафедры «Менеджмент»

Казанский инновачионный университет им. В.Г. Тимирясова ул. Московская, 42, г. Казань, Татарстан, 420111, Российская Федерация 
Хамидуллина Фания Рафиковна доцент, кандидат экономических наук

Казанский инновационный университет им. В.Г. Тимирясова ул. Московская, 42, г. Казань, Татарстан, 420111, Российская Федеращия

Арбузова Мария Владиславовна, преподаватель

Казанский филиал Волжского государственного университета водного транспорта

ул. Несмелова, 7, г. Казань, Татарстан 420030, Российская Федеращия

\section{DATA ABOUT THE AUTHORS}

Rimma S. Zaripova, Associate Professor, Candidate of Technical Sciences

Kazan State Power Engineering University

51, Krasnoselskaya Str., Kazan, Tatarstan, 420066, Russian Federation

zarim@rambler.ru

Olga A. Rocheva, Senior Lecturer of the Department

Kazan Innovative University named after $V$. G. Timiryasov 42, Moskovskaya Str., Kazan, Tatarstan, 420111, Russian Federation

Fania R. Khamidullina, Associate Professor, Candidate of Economic Sciences

Kazan Innovative University named after V. G. Timiryasov 42, Moskovskaya Str., Kazan, Tatarstan, 420111, Russian Federation

Maria V. Arbuzova, Lecturer

Kazan branch of the Volga State University of Water Transport 7, Nesmelova str., Kazan, Tatarstan, 420030, Russian Federation 